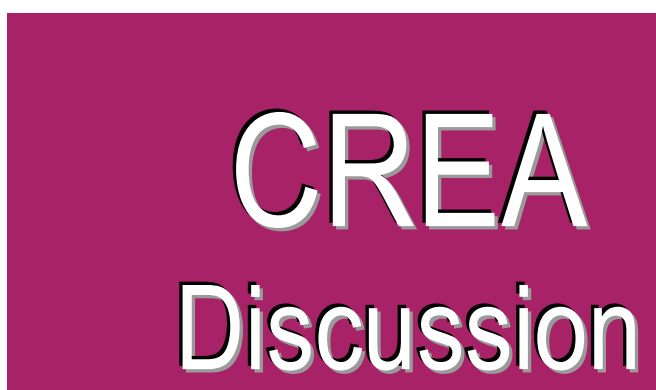
Paper 2019-04 Economics

\title{
Individual Attitudes towards Immigration in Aging Populations
}

available online : http://wwwfr.uni.lu/recherche/fdef/crea/publications2/discussion_papers

Rana Comertpay, CREA, Université du Luxembourg Andreas Irmen, CREA, Université du Luxembourg Anastasia Litina, CREA, Université du Luxembourg

March, 2019

For editorial correspondence, please contact: crea@uni.lu University of Luxembourg Faculty of Law, Economics and Finance

$162 \mathrm{~A}$, avenue de la Faïencerie L-1511 Luxembourg 


\title{
Individual Attitudes towards Immigration in Aging Populations
}

\author{
Rana Comertpay, Andreas Irmen; Anastasia Litina ${ }^{\S}$
}

\begin{abstract}
This research empirically establishes the hypothesis that the process of population aging in a society as a whole affects the attitudes of its members towards immigration. Hence, an aging social environment exerts an effect on the attitudes of individuals towards immigration after accounting for their age and other individual characteristics. We test this hypothesis in a multilevel analysis of individuals living in 25 European OECD countries over the period 2002-2017. Our measure of "societal population aging" is the old-age dependency ratio. "Attitudes" are taken from immigration related questions in eight consecutive rounds of the European Social Survey. For these attitudes we find non-linear, U-shaped relationships. Hence, the effect of societal population aging on individual attitudes towards immigration is negative in young societies and positive in old ones.
\end{abstract}

Keywords: Population Aging, Attitudes, Immigration, Culture

JEL-Classification: J1, Z1

This Version: March 13, 2019

${ }^{*}$ CREA, University of Luxembourg, Faculty of Law, Economics and Finance, 162a, Avenue de la Faïencerie, L-1511 Luxembourg (e-mail: rana.comertpay@uni.lu)

${ }^{\ddagger}$ CREA, University of Luxembourg, Faculty of Law, Economics and Finance, 162a, Avenue de la Faïencerie, L-1511 Luxembourg (e-mail: airmen@uni.lu), and CESifo, Munich

$\S$ Department of Economics, University of Ioannina, University Campus, 455 00, Ioannina Greece (e-mail:alitina@cc.uoi.gr)

Anastasia Litina and Andreas Irmen gratefully acknowledge financial support from the University of Luxembourg under the program "Agecon C-Population Aging: An Exploration of Its Effect on Economic Performance and Culture." The authors would like to thank Jordi Paniagua for feedback and suggestions during the 8th Immigration in OECD Countries conference as well audiences at the University of Luxembourg, at ASREC Europe 2018, at the 8th Annual International Conference "Immigration in OECD Countries," OECD Boulogne Conference Centre, and at the CREA Workshop "Culture and Comparative Development" for helpful comments and suggestions. 


\section{Introduction}

Attitudes towards immigration vary drastically within and across member states of the European Union ranging from outright hospitality to violent resistance. ${ }^{1}$ At the same time, the salience of immigration issues among the electorate is high and increasing (see, European Parliament (2017), p. 9). These tendencies challenge existing democratic parties and stimulate the emergence of new political movements, often at the expense of political stability. The response of European governments to future immigration flows and the design of integration policies is therefore likely to reflect these attitudes.

Hence, to predict and assess the political response to migration flows it is essential to comprehensively understand the determinants of individual attitudes towards immigration. This paper argues that societal population aging, defined as the process by which the older population becomes a proportionally larger fraction of the total population, is a determinant of individual attitudes towards immigration. To put it bluntly, we establish empirically that the attitudes towards immigration of an individual living in a young population systematically differ from the attitudes towards immigration of the same individual living in an old population. As population aging is ongoing in all countries included our sample this main finding helps predict the evolution of individual attitudes towards immigration and the political responses to it.

We establish the relationship between societal population aging and individual attitudes towards immigration in a multilevel analysis of individuals living in 25 European OECD countries over the period 2002-2017. Our measure of "societal population aging" is the old-age dependency ratio, henceforth OADR. "Attitudes" are taken from immigration related questions in eight consecutive rounds of the European Social Survey (ESS). ${ }^{2}$ There is population aging if the OADR increases over time. Figure 1 shows that the level of population aging measured by a country's OADR differs across countries of our sample. To a first approximation, there is population aging over the considered time span in all of these countries since the respective OADRs increase.

[Figure 1 about here]

A first, non-parametric exploration of the data suggests that the relationship

\footnotetext{
${ }^{1}$ For instance, Talo (2017) argues that Western European countries are on average much more open to immigration than Central and Eastern European countries. Within Germany attitudes to immigration are more positive in the western part of the country than in the east. See, e.g., The Economist (2015) on the European refugee crisis that started in 2015.

${ }^{2}$ We take ESS rounds 1 to 7 from European Social Survey Cumulative File, ESS 1-7 (2016) and ESS round 8 from ESS Round 8: European Social Survey Round 8 Data (2016).
} 
between individual attitudes towards immigration and societal population aging is non-linear. ${ }^{3}$ Our formal test of this suggestion reveals non-linear, U-shaped relationships. Hence, the effect of societal population aging on individual attitudes towards immigration is negative if the population is sufficiently young, i. e., the OADR is sufficiently small. However, beyond a critical level of the OADR, societal population aging induces more pro-immigrant attitudes with individuals.

To rationalize this finding one may think of two channels that potentially operate simultaneously and, taken together, may deliver an aggregate U-shaped relationship. ${ }^{4}$ The first channel explains why an attitude becomes more antiimmigrant as societal population aging increases. To develop an intuition for this observe first that in our sample older individuals are associated with more negative attitudes towards immigration. Hence, in an older society negative attitudes are likely to be more prevalent in everyday life, in the media, and in the political arena than in a younger one. Therefore, individuals living in an older society are more frequently reminded of the negative consequences of immigration and, following the logic of Tversky and Kahneman's Availability Heuristic, their attitudes adjust and become more anti-immigrant (Tversky and Kahneman, 1973).

The second channel describes why an attitude becomes more pro-immigrant as societal population aging increases. To understand this imagine a young country (with a low OADR) where competition in the job market is tough since the workforce is large. Then, new immigrants may be perceived by the native workforce as a serious threat to employment and a decent wage. As the population ages, e.g., due to a sustained decline in fertility, the number of workers falls. Accordingly, the job market may more easily accommodate immigrant workers as societal population aging eases competition in the labor market. For this reason individuals may develop more pro-immigrant attitudes.

To the best of our knowledge, our paper is the first that systematically disentangles the effect of societal population aging and individual aging on attitudes towards immigration. Existing contributions that focus on the role of individual aging patterns on attitudes towards immigration include Sides and Citrin (2007), Ivlevs (2012), Calahorrano (2013) and Schotte and Winkler (2016).

Sides and Citrin (2007) argue that characteristics of the overall state of the economy have little bearing on the formation of individual attitudes towards

\footnotetext{
${ }^{3}$ We would like to thank Jordi Paniagua for the suggestion to test first for the presence of non-linearities and then for the quadratic form. For more on this, see Section 4.1 below.

${ }^{4}$ In formal terms, the logic behind the mechanics of the two channels may be stated as follows. Let $\Omega>0$ denote the OADR. The first channel is represented by a function $f(\Omega)$ with $f^{\prime}(\Omega)<0$ and the second by a function $g(\Omega)$ with $g^{\prime}(\Omega)>0$. Then, the sum of these functions, $h(\Omega)=f(\Omega)+g(\Omega)$ is non-linear and U-shaped if there is a finite $\Omega^{*}$ such that $h^{\prime}\left(\Omega^{*}\right)=0$ and for all $\Omega>0$ we have $h^{\prime \prime}(\Omega)=f^{\prime \prime}(\Omega)+g^{\prime \prime}(\Omega)>0$.
} 
immigration. However, these authors restrict attention to the first round of the ESS, which captures only the period 2002-2003, and do not include the properties of the populations' age distribution in their analysis.

Ivlevs (2012) studies the formation of attitudes towards immigration in Latvia over the timespan 2004-2005 and concludes that a declining fertility rate in municipalities is conducive to more pro-immigrant attitudes. However, a declining fertility captures only one reason why populations age. In contrast, our study of a broad sample of countries over a long timespan uses a direct measure of population aging. Then, the aggregate effect of societal population aging and the formation of attitudes emerges as non-linear and U-shaped.

The study of Calahorrano (2013) focuses on Germany using the 2008 release of the German Socio-Economic Panel. Unlike our study with its focus on societal population aging, her paper deals with individual attitudes and cohort aging effects. The author finds a positive correlation between the age of an individual and its attitudes towards immigration.

Finally, Schotte and Winkler (2016) investigate why the elderly, i. e., older cohorts, tend to be more averse to immigration than their younger peers. Using the first six rounds of the ESS for the timespan 2002-2013, the authors find that the correlation between individual age and pro-immigration attitudes is either negative or zero in most of the countries in the sample. Nevertheless, the study is mute on the role of societal population aging for the formation of individual attitudes towards immigration.

Our study extends and complements the above-mentioned literature in at least in two ways. First, we establish that societal population aging, on top of other age-related individual or cohort measures, is a significant determinant of attitudes towards immigration. Second, we document that the relationship between societal population aging and attitudes towards immigration emerges as non-linear and U-shaped.

The remainder of our paper is structured as follows. Section 2 describes the data (Section 2.1) and our empirical strategy (Section 2.2). Our main findings are presented in Section 3. Section 4 starts with a test of the presence of a Ushaped relationship between societal population aging and individual attitudes towards immigration (Section 4.1). Then, it shows that our findings survive various robustness tests (Section 4.2). Section 5 elaborates more on our empirical findings and studies the effect of societal population aging on a range of immigration related attitudes such as i) preferences for the ethnic background of immigrants (Section 5.1 ), ii) the expected socio-economic contributions of immigrants (Section 5.2), and iii) cultural homogeneity, education and work skills of immigrants (Section 5.3). Finally, we discuss whether the effect of societal population aging on individual 
attitudes towards immigration is driven by an age group in our sample (Section 5.4). Section 6 concludes. All tables and figures are relegated to Section 7, the Appendix.

\section{$2 \quad$ Data and Empirical Strategy}

\subsection{The Data}

To explore the effect of an aging population on attitudes towards immigration, we employ data from eight rounds of the ESS covering the period from 2002 to 2017. We conduct a multilevel analysis combining country-level and individual-level controls in a sample of 25 OECD countries including Austria, Belgium, Czech Republic, Denmark, Estonia, Finland, France, Germany, Greece, Hungary, Iceland, Ireland, Italy, Luxembourg, Netherlands, Norway, Poland, Portugal, Slovakia, Slovenia, Spain, Sweden, Switzerland, Turkey, and the United Kingdom. For these countries the full set of controls for our benchmark analysis is available. ${ }^{5}$

\section{Aggregate Controls}

Our main explanatory variable is the OADR. It measures societal population aging at the country level. The data is taken from the World Development Indicators, henceforth WDI. The OADR states the number of people above the age of 65 -the old- per 100 people of the working population aged 15-64. ${ }^{6}$

The remaining controls include income per capita, birth rate, life expectancy, population density, unemployment, and urban population growth. These variables qualify as plausible determinants of attitudes towards immigration that capture the stage of development, other demographic factors as well as socioeconomic determinants. We also control for the stock of a country's foreign population taken from the OECD International Migrant Database ("OECD IMD"). ${ }^{7}$ This variable does not exist for Israel, which we therefore exclude from our sample. The OECD data provide the measure of a country's foreign population both by birth and by

\footnotetext{
${ }^{5}$ Focusing the analysis on a sample of OECD countries ensures that all countries under examination completed the demographic transition and, thus, population aging is not only a plausible concern but also part of the policy makers agenda. A number of studies suggest that in countries at the onset of the demographic transition population aging is not yet a concern since the "boom generation" is still active (Bloom et al., 2008).

${ }^{6}$ In Section 4 we replace the OADR as defined above by an alternative definition of the dependency ratio, namely, the number of people aged 65 and over per 100 members of the total population. With this measure of societal population aging our main results still hold.

${ }^{7}$ The OECD IMD has data showing flows and stocks of the total immigrant population and immigrant labor force together with data on the acquisition of nationality (OECD, 2018).
} 
nationality. Here, we use the stock of foreign population by nationality. ${ }^{8}$ We then aggregate both the WDI and OECD IMD data over 2-year intervals to match the intervals of the ESS.

Descriptions and some summary statistics on the variables that we use are provided in Table 1. The mean OADR is 24.92 varying from 10.04 in Turkey in the period 2004-2005 to 35.97 in Italy in the period 2016-2017. In addition, Figure 1 shows the evolution of the OADR over time for the 25 countries of our sample over the period 2002 to 2017. Some interesting patterns emerge. With the exception of Luxembourg, there is a strict increase in the OADR for all countries. The OADR in countries such as Austria, Belgium, Denmark, Estonia, Finland, France, Germany, Greece, Hungary, Italy, Poland, Portugal, Spain, Slovenia, and Sweden considerably increased over the last 10 years and reached levels beyond 27-28. Countries like Iceland, Ireland, Slovakia, and Turkey have a relatively lower OADR. Nevertheless their OADRs also increased. Turkey has by far the lowest OADR of all countries in the sample. ${ }^{9}$ In Luxembourg the OADR remains fairly stable over the considered time span.

Table 1 also shows that the mean annual income for the sample is 39,550 in constant 2010 US dollars. The average life expectancy at birth is 79 years. The average value of live births is approximately equal to 11 per 1000 mid-year members of the total population. The average unemployment rate is $8.12 \%$. The mean annual urban population growth rate is $0.71 \%$. The population density is approximately at 145 people per square $\mathrm{km}$ of land area. The average foreign population by nationality is roughly 1.7 million people.

\section{Individual Attitudes and Controls}

We obtain individual attitudes towards immigration and a wide array of individual controls from the ESS. The individual characteristics include age, education, gender, marital status, living with children, source of income, religious denomination, and belonging to an ethnic minority in a country. Descriptions and some summary statistics on these variables are provided in Table 2.

Our proxies for the attitudes of individuals towards immigration are their responses to the following six questions of the ESS:

\section{Allow many/few immigrants of same race/ethnic group as majority}

\footnotetext{
${ }^{8}$ Boeri (2010) mentions the difficulty of defining immigrant status when studying the fiscal position of migrants in Europe using the EU-SILC data. Indeed, when immigrants are identified based on their country of birth, this author notices the likelihood of committing the error of misclassifying true nationals as being immigrants when they are, for whatever reason, born abroad. However, the author also acknowledges that one does not account for cross-country differences in naturalization laws when immigrant status is defined based on nationality.

${ }^{9}$ To this end we conduct a robustness test excluding Turkey (see Section 4). This, however, does not affect our main results.
} 
2. Allow many/few immigrants of different race/ethnic group from majority

3. Allow many/few immigrants from poorer countries outside Europe

4. Immigration bad or good for country's economy

5. Country's cultural life undermined or enriched by immigrants

6. Immigrants make country worse or better place to live.

These questions are available in all eight rounds of the ESS covering the period 2002-2017 and across all 25 countries of our sample. Our benchmark analysis is therefore based on individual reactions to the above-mentioned questions.

As can be seen from Table 3, of these six questions the first three have an average score of 2.5 out of 4 . The average score for the remaining three questions is approximately 5 out of 10 . Everywhere, higher indicated values reflect a more positive attitude towards immigration.

In an attempt to provide a better understanding of these attitudes, we grouped the above six questions using the method of factor analysis into two categories

I. Allowing what Kind of Immigrants to the Host Country

II. Perceptions about the Socio-Economic Contributions of Immigrants to the Host Country.

Beyond the above-mentioned six questions, the ESS has additional ones of interest that provide further information on the evolution of individual attitudes towards immigration. However, these questions are only available for a limited number of years and a restricted number of countries. Therefore, we use them only in Section 5, the discussion section. These questions include

7. Allow many/few immigrants from poorer countries in Europe

8. Taxes and services: immigrants take out more than they put in or less

9. Immigrants take jobs away in country or create new jobs

10. Immigrants make country's crime problems worse or better

11. Qualifications for immigration: Christian background

12. Qualifications for immigration: committed to way of life in country

13. Qualifications for immigration: good educational qualifications 
14. Qualifications for immigration: speak country's official language

15. Qualifications for immigration: be white

16. Qualifications for immigration: work skills needed in country. ${ }^{10}$

The total number of individual observations in our sample of 25 European OECD countries is approximately equal to 315,000 .

\subsection{Empirical Strategy}

This section introduces our benchmark analysis, which is described by

$$
I_{j i t}=\beta_{0}+\beta_{1} \Omega_{i t}+\beta_{2} \Omega_{i t}^{2}+\beta_{3} Z_{j i t}+\beta_{4} X_{i t}+\beta_{5} C_{i}+\beta_{6} T_{t}+\epsilon_{j i t} .
$$

Here, $I_{j i t}$ is the attitude towards immigration of individual $j$ in country $i$ at ESS round $t$. The OADR is denoted by $\Omega_{i t}$, whereas $\Omega_{i t}^{2}$ is its squared value. The presence of the quadratic term allows for the identification of a non-linear effect of societal population aging on individual attitudes towards immigration. We use the contemporaneous values of the OADR in our benchmark analysis. This suggests a contemporaneous effect of societal population aging on attitudes towards immigration. ${ }^{11}$

Our benchmark analysis contains a vector of confounders, $X_{i t}$, which includes a large number of time-varying country-level controls that may have an effect on attitudes towards immigration. The right-hand side also shows a vector $Z_{j i t}$, which includes a number of time-varying individual-level controls that may also affect the attitudes towards immigration. The vector of country fixed effects, $C_{i}$, captures unobserved heterogeneity at the country level, at least for time-invariant characteristics such as geography and climate. The vector of year fixed effects, $T_{t}$, captures time-specific shocks, e.g., the presence of the baby-boom generation across countries. We denote the country and time-specific error term by $\epsilon_{j i t}$. The standard errors are clustered at both, the year (ESS round) and the country level.

As mentioned above, we group the six questions about immigration in the ESS into two main categories and then perform a factor analysis within each group of questions. Hence, for $k=I, I I$, our empirical specification of the factor analysis is

\footnotetext{
${ }^{10}$ As can be seen from Table 4 , of these ten questions the first has an average score of 2.5 out of 4 . The average score for the following three questions is 4 out of 10 . The last six questions have an average score of 4.5 out of 10. Again, higher indicated values reflect everywhere a more positive attitude towards immigration.

${ }^{11}$ As shown in Section 4, our results are robust to the use of lagged values of the OADR.
} 


$$
f_{k j i t}=\beta_{0}+\beta_{1} \Omega_{i t}+\beta_{2} \Omega_{i t}^{2}+\beta_{3} Z_{j i t}+\beta_{4} X_{i t}+\beta_{5} C_{i}+\beta_{6} T_{t}+\epsilon_{k j i t} .
$$

Here, $f_{k j i t}$ is the attitude towards immigration of individual $j$ in country $i$ at ESS round $t$ that belongs to category $k$.

\section{$3 \quad$ Key Findings}

This section develops the empirical findings for our benchmark analysis. They are shown in Tables 5 and 6 . Table 5 has the results for category $k=I$, Table 6 those for category $k=I I$. Column (1) of both tables has the regression specification that only includes year and country fixed effects.

Column (2) of the tables introduces individual age and its squared term as controls. This allows for the distinction between an individual age effect and the effect of societal population aging. Clearly, the age of the individual respondent has a negative effect on its attitudes towards immigration whereas the effect of societal population aging remains U-shaped. Column (3) enriches the analysis with more individual-level controls including education, gender, marital status, living with children, source of income, religious denomination, and belonging to an ethnic minority in a country.

The remaining columns gradually introduce our additional country-level and time-varying controls available for our benchmark analysis. More precisely, in column (4), we control for income per capita to capture the stage of development of a country, in column (5), we introduce the stock of foreign population by nationality, in column (6), birth rates and life expectancy are added. Column (7) includes the unemployment rate. ${ }^{12}$ Finally, column (8) adds population density and urban population growth rate as additional demographic controls. Since column (8) includes the full set of controls, we shall refer to this specification as our benchmark analysis.

The estimated values of $\beta_{1}$ are strictly negative whereas the estimated values of $\beta_{2}$ are strictly positive. Hence, the effect of societal population aging on individual attitudes towards immigration is U-shaped.

As illustrated in Figure 2, this implies a strictly positive critical OADR, $\hat{\Omega}=$ $-\beta_{1} /\left(2 \beta_{2}\right)$. On the one hand, if $\Omega_{i t}<\hat{\Omega}$, then in country $i$ attitudes towards immigration become more negative when the OADR increases a bit further. On the other hand, if $\Omega_{i t}>\hat{\Omega}$, then in country $i$ attitudes towards immigration become more positive when the OADR increases further.

\footnotetext{
${ }^{12}$ Interestingly, in Tables 5 and 6 , higher unemployment rates are associated with more hostility towards immigration.
} 
[Figure 2 about here]

The critical OADR for $k=I$ is equal to 32 whereas for $k=I I$, it is equal to 28.5. That implies for $k=1$ that in the period 2016-2017 countries such as Germany, Finland, Italy, and Portugal with respective OADRs equal to $32,60,33,55,35,97$, and 32,82 find themselves on the increasing part of the $U$. In the same period, the remaining countries are on the decreasing part. These numbers suggest that the level of the critical OADR is not unrealistic. However, it is important to note that the critical OADR is a number that is derived for all countries in the sample conditional on the full set of controls. It is not specific to a particular country and neither an unconditional result.

\section{Robustness}

\subsection{Non-linear Specification}

As already discussed in the introduction, we do not impose a quadratic specification. Instead, we test for the presence of a U-shaped relationship between societal population aging and individual attitudes towards immigration. In doing so, we follow Lind and Mehlum (2010). These authors suggest that an appropriate test determines whether on some interval of values of the explanatory variable, the relationship in question is decreasing at low values within this interval and increasing at high values. Our application of this test is shown in Table 7 . Our results clearly suggest a U-shaped relationship. Moreover, the value at which the minimum occurs is very close to the critical OADR in our benchmark analysis, i. e., roughly 30. In light of this finding, we use in our benchmark analysis the standard approach including a quadratic term and a test of covariates.

\subsection{Alternative Specifications}

We also conduct several robustness tests to corroborate the validity of our results under a number of different assumptions that require alternative specifications. Table 8 summarizes our findings. Columns (1) and (2) correspond respectively to $k=I$ and $k=I I$. Each numbered line of the table corresponds to a robustness test performed on our benchmark analysis. For each of these tests, we report both the effect of the OADR and its squared term. We also report the critical OADR for each specification.

In Line 1 of Table 8, we conduct a regional analysis in a panel of 98 NUTS 1 
regions in 24 European OECD countries. ${ }^{13}$ This allows for the inclusion of a large number of unobservables and helps to eliminate unobserved heterogeneity at the regional level. Eurostat provides the regional annual data for the period 2002-2017.

As in our benchmark analysis, for $k=I, 2$, our empirical specification of the factor analysis is

$$
f_{k j r t}=\beta_{0}+\beta_{1} \Omega_{r t}+\beta_{2} \Omega_{r t}^{2}+\beta_{3} Z_{j r t}+\beta_{4} W_{r t}+\beta_{5} T_{t}+\beta_{6} R_{r}+\epsilon_{k j r t}
$$

Here, $f_{k j r t}$ is the attitude towards immigration of individual $j$ in region $r$ at ESS round $t$ that belongs to category $k$. The OADR is denoted $\Omega_{r t}$ whereas $\Omega_{r t}^{2}$ is its squared value. We use the contemporaneous values of the OADR in our benchmark analysis. This suggests a contemporaneous effect of population aging on attitudes towards immigrants. Our benchmark analysis contains a vector of confounders, $W_{r t}$, which includes a large number of time-varying controls that may have an effect on attitudes towards immigrants as well as a vector $Z_{j r t}$ including a number of time-varying and individual-level controls. The vector of region fixed effects, $R_{r}$, captures unobserved heterogeneity at the regional level, at least for time-invariant characteristics such as geography and climate. The vector of year fixed effects, $T_{t}$, captures time-specific shocks, e.g., the presence of the baby-boom generation across countries. Finally, $\epsilon_{j r t}$ is the region and time-specific error term. The standard errors are clustered at both, the year (ESS round) and the country level.

As observed from Table 8, our findings are similar to our benchmark analysis. The effect of societal population aging on attitudes towards immigration at the NUTS 1 level is also U-shaped. The critical OADR, for $k=I$ is 26 , for $k=I I$, it is 25 .

In Line 2 we use a different definition of the OADR. More precisely, we now consider the ratio of the population above 65 as a fraction of the total population. All findings of our benchmark analysis remain intact, i. e., the relationship between attitudes towards immigration and societal population aging remains U-shaped. Naturally, as the OADRs under the new definition are lower so is the critical OADR.

In Line 3 we replace the contemporaneous OADR by a lagged value to address potential concerns about reverse causality. More precisely, for every round of the ESS we use the OADR corresponding to the previous round. The estimates we find are significant and similar in magnitude to our benchmark analysis. In particular, the relationship between attitudes towards immigration and societal population aging remains U-shaped.

\footnotetext{
${ }^{13}$ We have to exclude Luxembourg as for this country the relevant regional-level controls are not available.
} 
In Line 4 we focus on the subsample of individuals with citizenship in their country of residence. This is meant to check whether our results are driven by the attitudes of immigrants without a citizenship, who may be more sympathetic towards further immigration. However, the results of our benchmark analysis survive this robustness test, too. If anything, the critical OADRs are slightly more pronounced.

Finally, in Line 5 we remove Turkey from our sample to scrutinize whether this country has the status of an outlier that significantly influences our results. However, this is not the case.

\section{Discussion and Extensions}

In this section we exploit the above-stated questions 7 to 16 of the ESS to better understand the mechanics that drive individual attitudes towards immigration (Sections 5.1 to 5.3). These questions are only available for the ESS rounds 1 and 7 and were not asked in Iceland, Slovakia and Turkey. Finally, Section 5.4 addresses the question of the potential role of cohort effects.

\subsection{Do Aging Societies have a Preference for Immigrants with a Particular Ethnic Background?}

Table 9 suggests that the answer may be yes. Here, in Columns (1) to (4), we use as the dependent variable the attitudes expressed in Questions 1, 2, 3, and 7 of the ESS.

However, the critical OADR for Question $2(\operatorname{Column}(2))$ is significantly smaller than the one for Question 1 (Column (1)). In other words, individuals prefer receiving additional immigrants with a different ethnic background from those who are already present. This potentially reflects a fear for a dominating ethnic group that may too strongly influence societal life.

The critical OADRs for Questions 3 and 4 are roughly the same. If anything, the critical OADR for attitudes towards immigrants from poorer countries outside Europe is lower than for European immigrants. 


\subsection{Do Attitudes towards Immigration in Aging Societies hinge on the Expected Socio-Economic Contribution of Immigrants?}

Table 10 suggests that the answer depends on the sort of socio-economic contribution. Here, in Columns (1) to (6), we use as the dependent variable the attitudes expressed in Questions 4, 5, 6, 8, 9, and 10 of the ESS.

The lowest critical OADR obtains in Column (4). This suggests that individuals in aging societies understand that immigrants contribute positively to society, e. g., with the taxes they pay. The highest critical OADR appears in Column (3). Hence, individuals in aging societies tend to find it harder to associate immigrants as improving the quality of life in their country. Interestingly however, aging societies do not perceive immigrants as worsening crime problems.

\subsection{Education and Work Skills versus Cultural Homogene- ity - What Matters more for Aging Societies?}

Table 11 gives a clear answer. Here, in Columns (1) to (6), we use as the dependent variable the attitudes expressed in Questions 11, 12, 13, 14, 15, and 16 of the ESS.

Attitudes towards immigration are more positive if immigrants have good educational qualifications and the work skills needed in the host country (See Columns (3) and (6)). However, cultural homogeneity does not seem to have a significant effect on individual attitudes towards immigration. This is true for the Christian background of immigrants, their commitment to the way of life in the host country, their ability to speak the host country's official language, and to be white (Columns (1), (2), (4), and (5)).

\subsection{Is the Effect of Societal Population Aging on Individ- ual Attitudes towards Immigration Driven by an Age Group in the Sample?}

To address this question, we focus on two age groups in the sample, the young and the old. Then, we want to know whether societal population aging affects the attitudes of these two age groups differently. If this was the case, then our results may be driven by an age group effect. However, we find that the effect of societal population on the attitudes towards immigration of both the young and the old is very similar.

To derive this result, we first interact our explanatory variable, the OADR, 
with a dichotomous variable for individuals aged 64 and below (the young) and for individuals aged 65 and over (the old). In this specification the underlying assumption is that only the effect of OADR on individual attitudes towards immigration differs by age group. As can be seen from Panel I in Table 12, both groups contribute equally to the effect of societal population aging on individual attitudes towards immigration. The coefficients are similar in magnitude and have the same sign. The critical OADRs are similar to those of our benchmark analysis.

Second, we split the sample according to individuals' age into two subsamples, on the one hand individuals aged 64 and below (the young), on the other hand individuals aged 65 and over (the old). Here, our assumption is stronger since we stipulate that the two age groups differ in all dimensions we control for, including of course the effect of the OADR on attitudes. As can be seen from Panel II in Table 12, both groups contribute equally to the effect of societal population aging on individual attitudes towards immigration. Again, the coefficients are similar in magnitude and have the same sign. Moreover, the critical OADRs are also similar to those of our benchmark analysis.

Hence, we conclude from Panel I and II that our results are not driven by age groups. Rather, they reflect the effect of overall societal population aging.

\section{Concluding Remarks}

This study establishes two main results. First, societal population aging is a significant determinant of attitudes towards immigration. Second, the relationship between societal population aging and attitudes towards immigration is U-shaped. Accordingly, our study predicts that the effect of societal population aging on individual attitudes towards immigration is negative in young societies and positive in old ones.

\section{Appendix: Tables and Figures}

This appendix includes tables and figures to which we refer in the main text. 


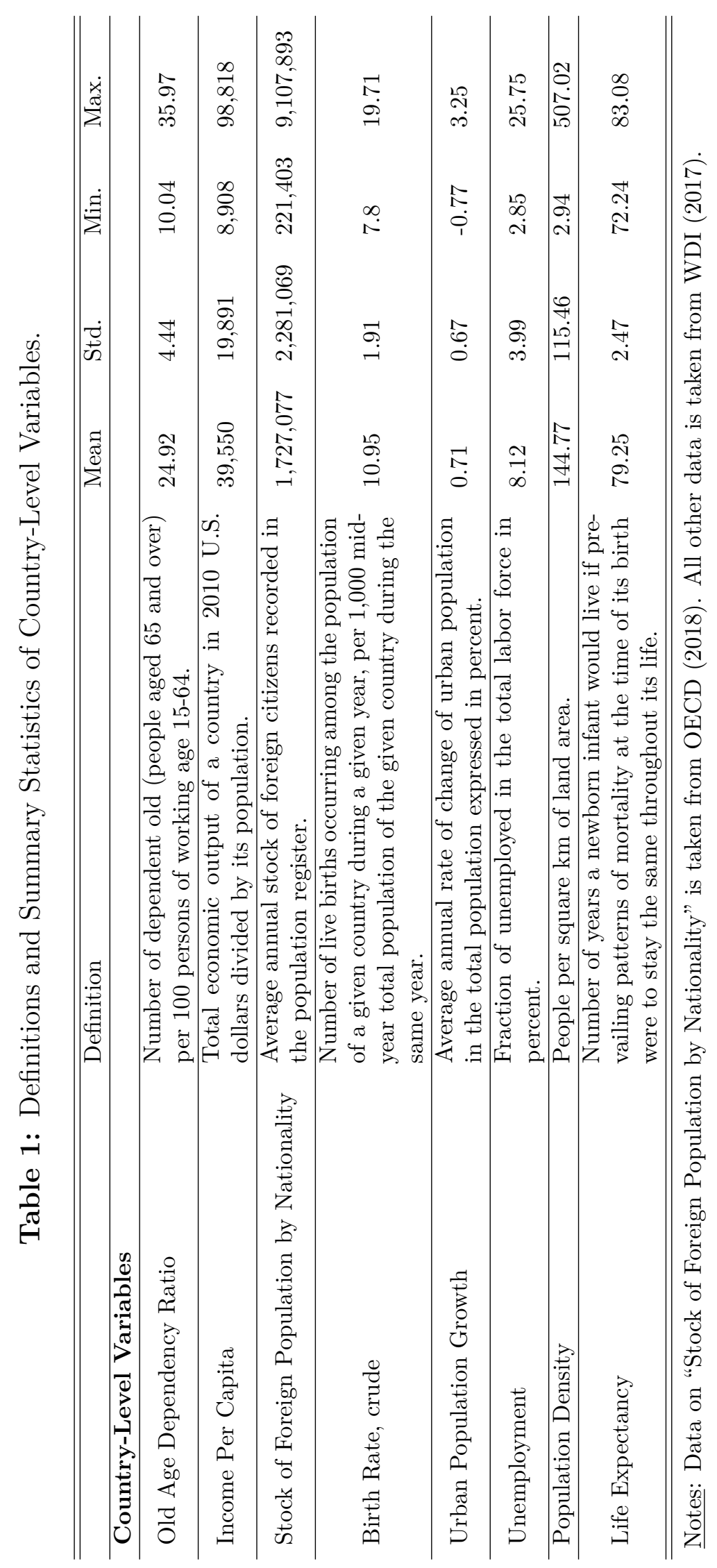




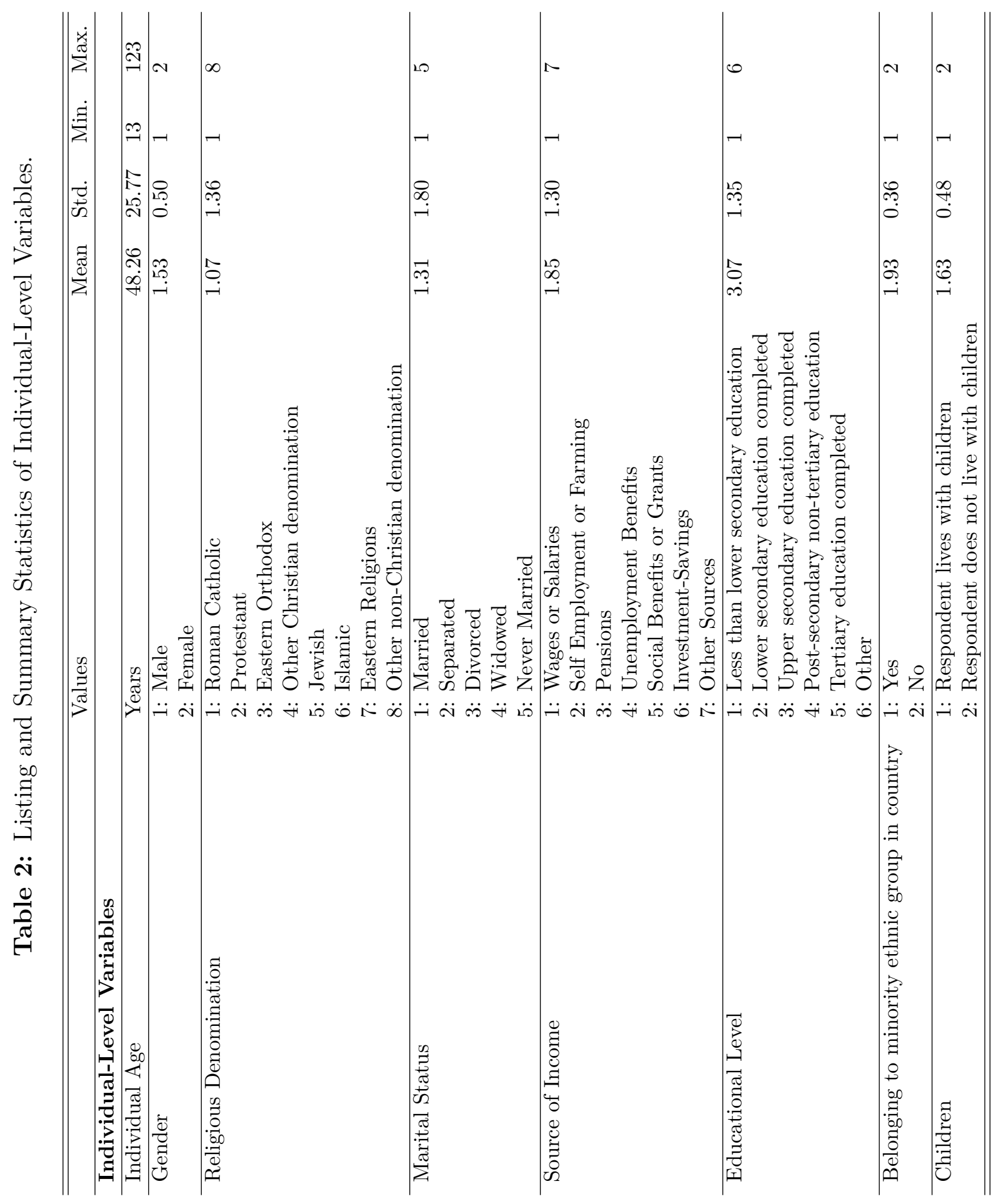




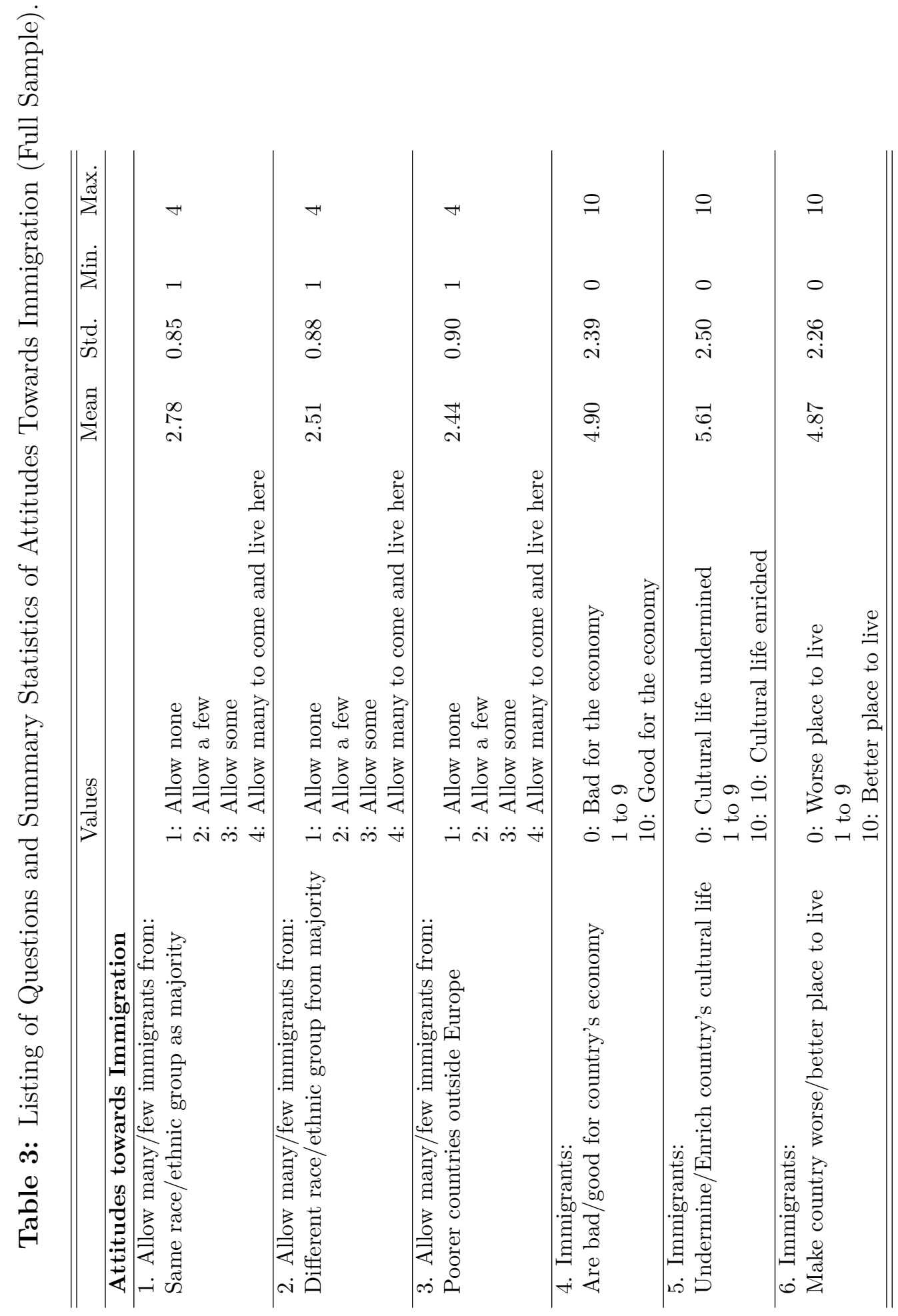




of

(1)

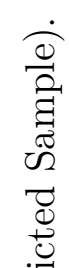

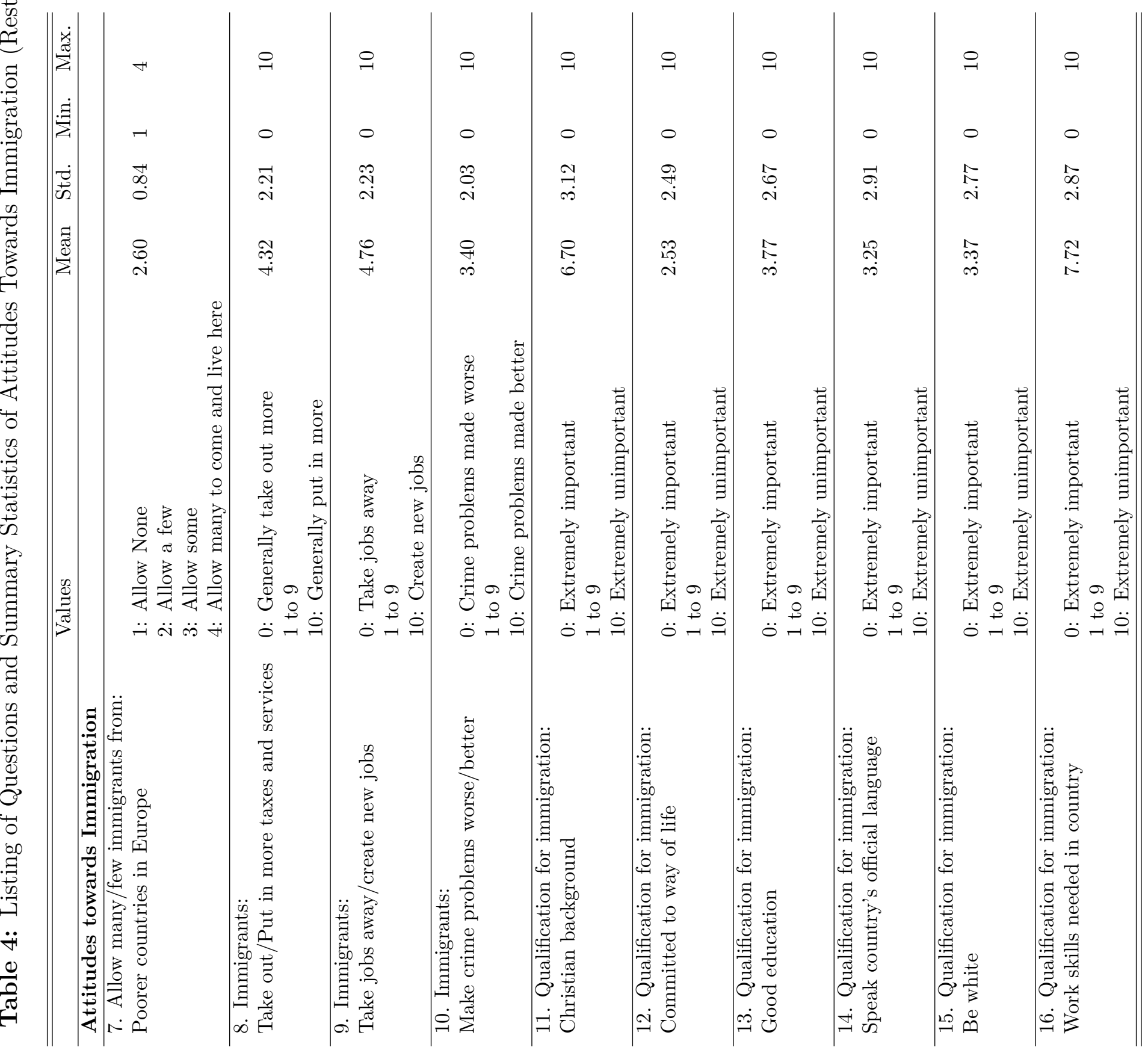




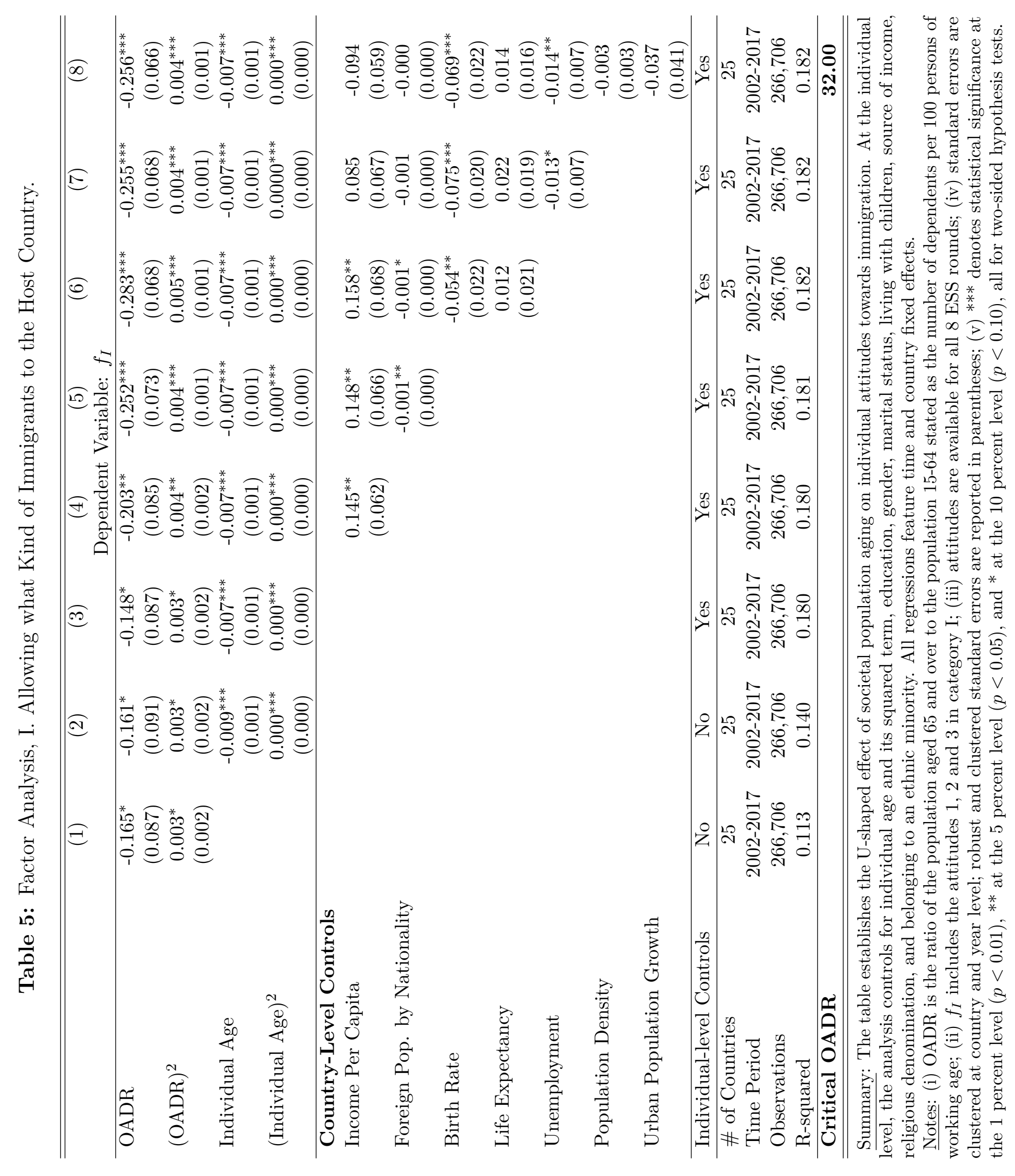




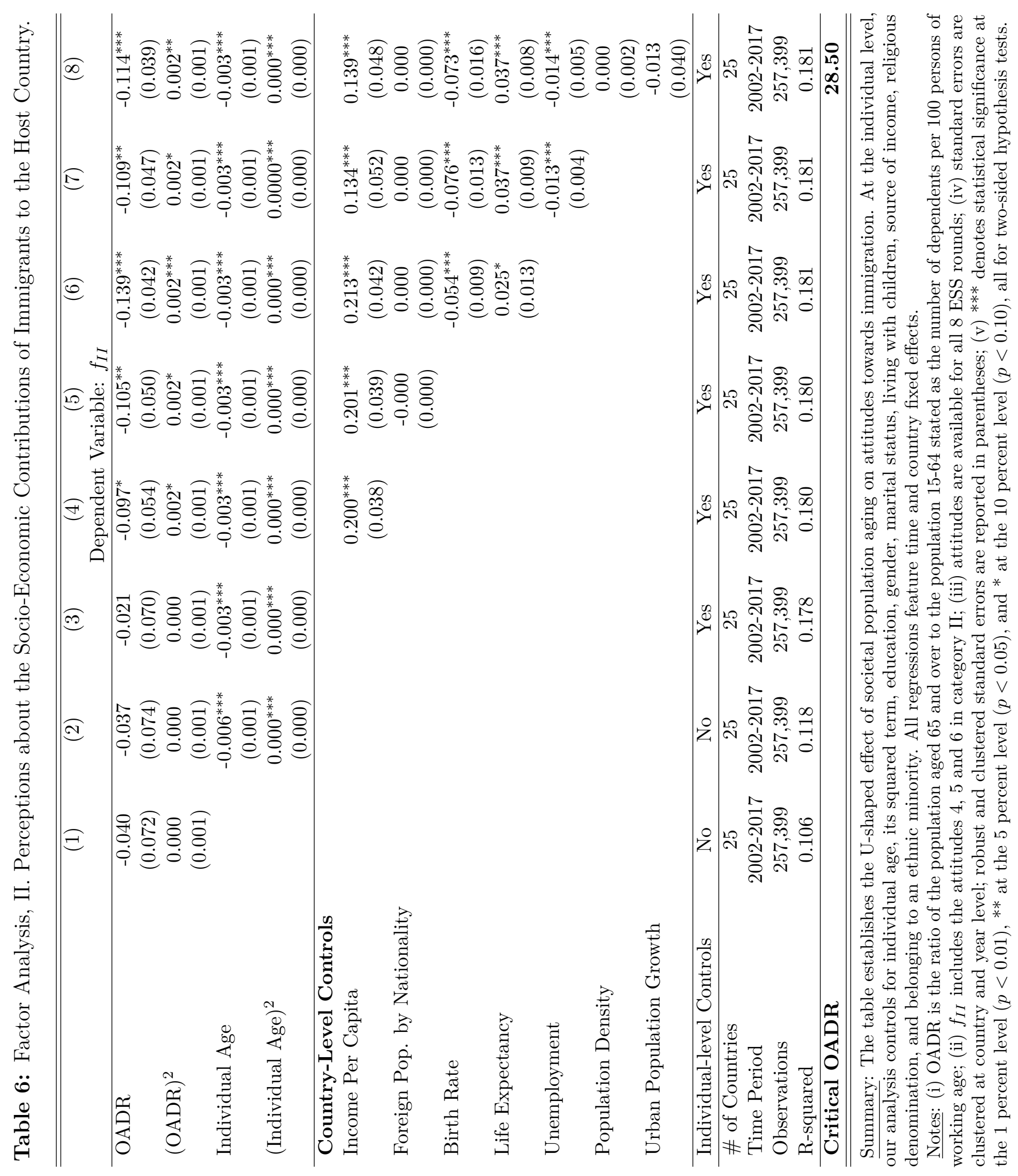


Table 7: Results from the Test for a U-shaped Relationship.

Specification: $\mathrm{f}(x)=x^{2}$

Extreme Point: 30.6527

Test:

H1: U shape

vs. H0: Monotone or

Inverse U shape

\begin{tabular}{lcc} 
& Lower Bound & Upper Bound \\
\hline Interval & 10.04287 & 35.96815 \\
Slope & -0.1723394 & 0.0444478 \\
t-value & -3.925397 & 1.881223 \\
$\mathrm{P}>|\mathrm{t}|$ & 0.0000433 & 0.0299713 \\
\hline
\end{tabular}

Overall test of a presence

of a U shape:

$\mathrm{t}$-value $=1.88$

$\mathrm{P}>|\mathrm{t}|=0.03$ 
Table 8: Robustness Tests.

\begin{tabular}{|c|c|c|}
\hline & $\begin{array}{c}(1) \\
\text { Dependen } \\
f_{I}\end{array}$ & $\begin{array}{c}(2) \\
\text { Variable: } \\
f_{I I}\end{array}$ \\
\hline \multicolumn{3}{|l|}{ Line 1} \\
\hline OADR regional level & $\begin{array}{c}-0.156^{* * *} \\
(0.044)\end{array}$ & $\begin{array}{c}-0.100^{* * *} \\
(0.034)\end{array}$ \\
\hline$(\mathrm{OADR})^{2}$ regional level & $\begin{array}{c}0.003^{* * *} \\
(0.001)\end{array}$ & $\begin{array}{c}0.002^{* * *} \\
(0.001)\end{array}$ \\
\hline Critical OADR & 26.00 & 25.00 \\
\hline \multicolumn{3}{|l|}{ Line 2} \\
\hline Old Above 65 Ratio & $\begin{array}{c}-0.473^{* * *} \\
(0.133)\end{array}$ & $\begin{array}{c}-0.193^{\text {*** }} \\
(0.081)\end{array}$ \\
\hline 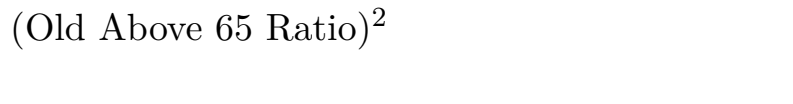 & $\begin{array}{c}0.012^{* * *} \\
(0.003)\end{array}$ & $\begin{array}{l}0.004^{*} \\
(0.002)\end{array}$ \\
\hline Critical OADR & 19.71 & 24.13 \\
\hline \multicolumn{3}{|l|}{ Line 3} \\
\hline OADR Lagged & $\begin{array}{c}-0.253^{* * *} \\
(0.066)\end{array}$ & $\begin{array}{c}-0.112^{* * *} \\
(0.040)\end{array}$ \\
\hline$(\mathrm{OADR})^{2}$ Lagged & $\begin{array}{c}0.004^{* * *} \\
(0.001)\end{array}$ & $\begin{array}{c}0.002^{* * *} \\
(0.001)\end{array}$ \\
\hline Critical OADR & 31.63 & 28.00 \\
\hline \multicolumn{3}{|l|}{ Line 4} \\
\hline OADR surveyed individuals hold citizenship & $\begin{array}{c}-0.269^{* * *} \\
(0.068)\end{array}$ & $\begin{array}{c}-0.122^{\text {*** }} \\
(0.042)\end{array}$ \\
\hline$(\mathrm{OADR})^{2}$ surveyed individuals hold citizenship & $\begin{array}{c}0.004^{* * *} \\
(0.001)\end{array}$ & $\begin{array}{c}0.002^{* * *} \\
(0.001)\end{array}$ \\
\hline Critical OADR & 33.63 & 30.50 \\
\hline \multicolumn{3}{|l|}{ Line 5} \\
\hline OADR Turkey excluded from the sample & $\begin{array}{c}-0.256^{* * *} \\
(0.066)\end{array}$ & $\begin{array}{c}-0.114^{* * *} \\
(0.039)\end{array}$ \\
\hline$(\mathrm{OADR})^{2}$ Turkey excluded from the sample & $\begin{array}{c}0.004^{* * *} \\
(0.001)\end{array}$ & $\begin{array}{c}0.002^{* * *} \\
(0.001)\end{array}$ \\
\hline Critical OADR & 32.00 & 28.50 \\
\hline
\end{tabular}

Summary: This table displays the results of robustness tests that are conducted on the U-shaped effect of societal population aging on individual attitudes towards immigrants. Controls are the same as in our benchmark analysis. All regressions feature time and country fixed effects.

Notes: (i) OADR is the ratio of the population aged 65 and over to the population 15-64 stated as the number of dependents per 100 persons of working age; (ii) $f_{I}$ includes the attitudes 1,2 and 3 ; (iii) $f_{I I}$ includes the attitudes 4,5 and 6; (iv) standard errors are clustered at country and year level; (v) robust and clustered standard errors are reported in parentheses; (vi) *** denotes statistical significance at the 1 percent level $(p<0.01),{ }^{* *}$ at the 5 percent level $(p<0.05)$, and ${ }^{*}$ at the 10 percent level $(p<0.10)_{22}$ all for two-sided hypothesis tests. 


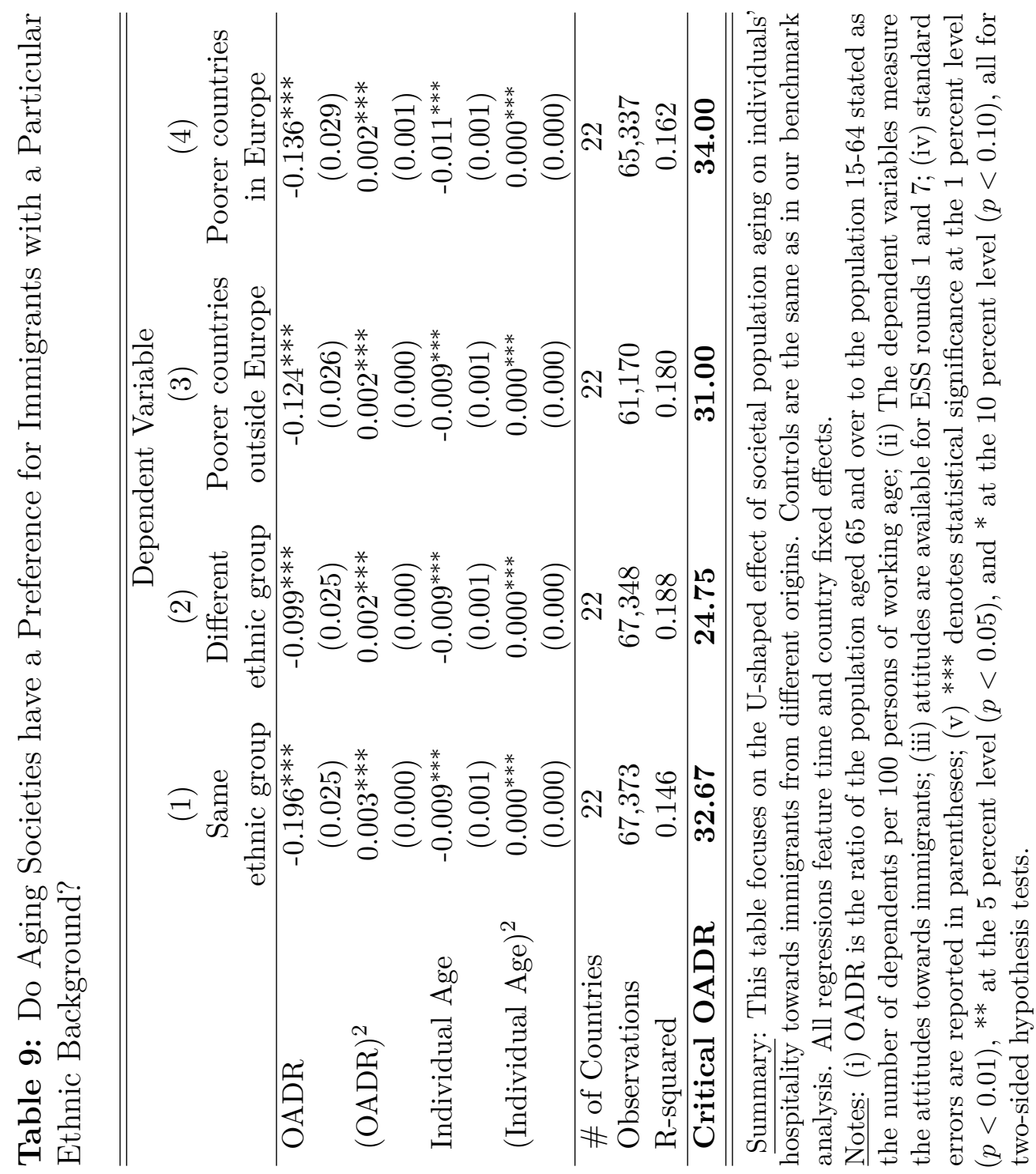




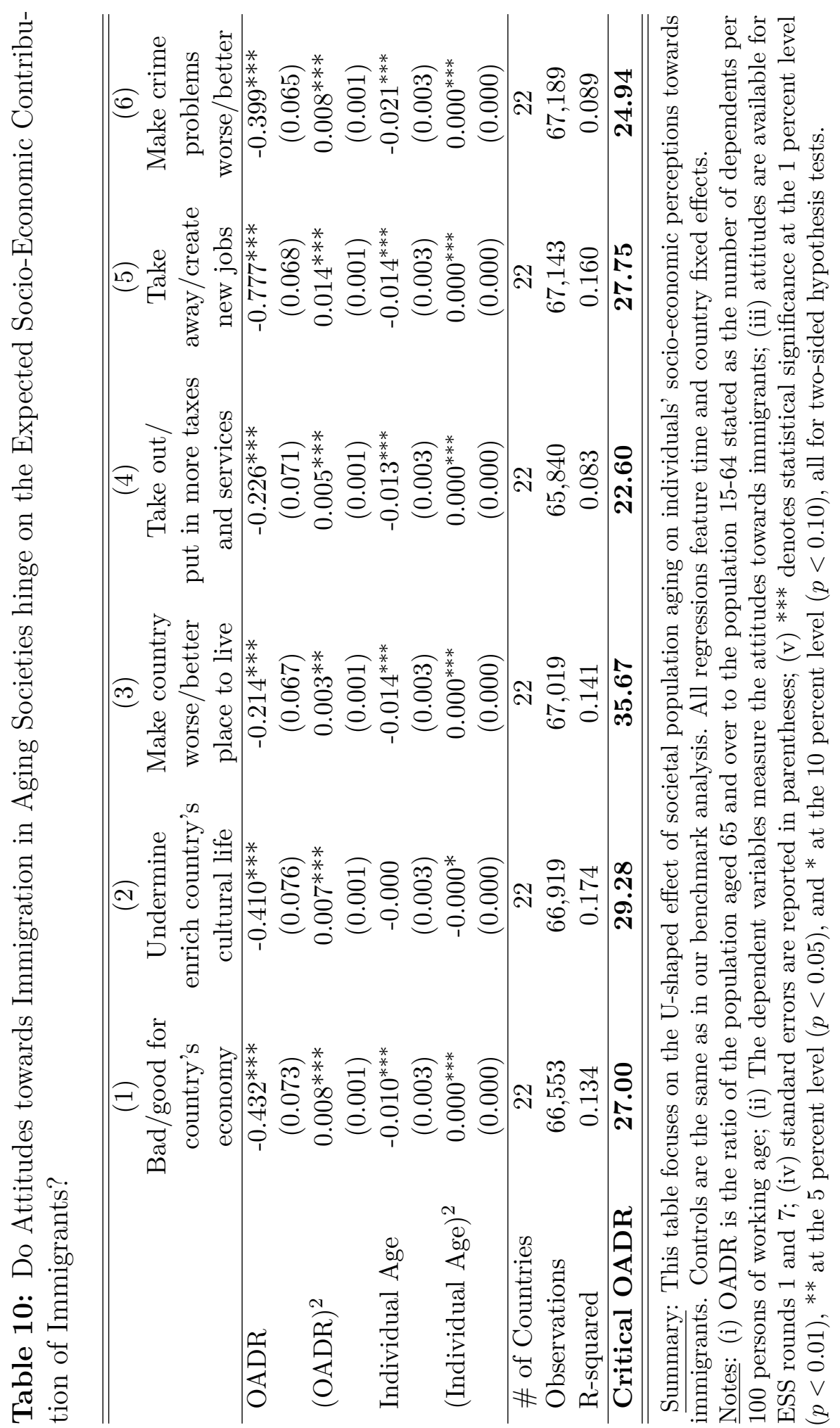




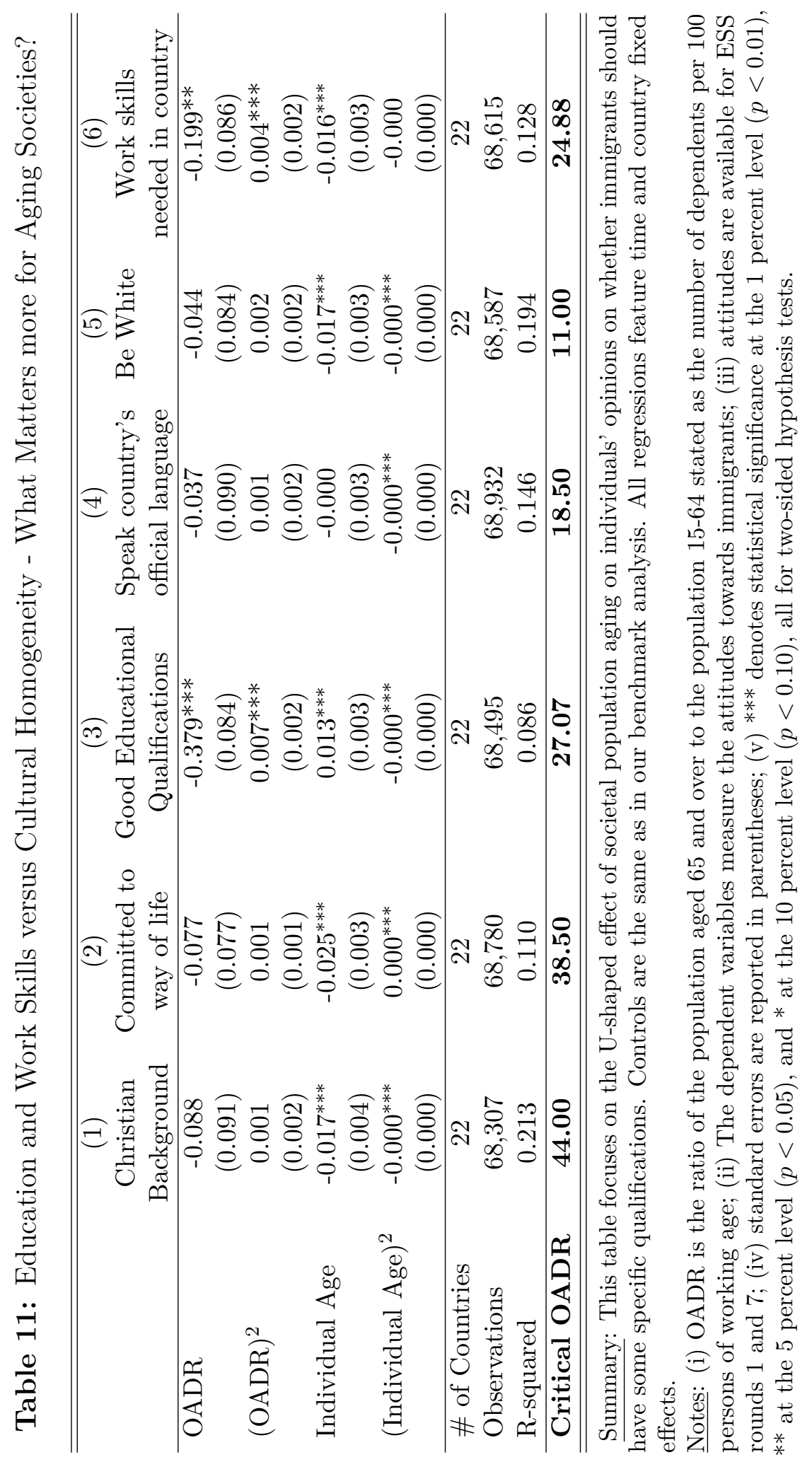


Table 12: Is the Effect of Societal Population Aging on Individual Attitudes towards Immigration Driven by an Age Group in the Sample?

\begin{tabular}{|c|c|c|}
\hline & $\begin{array}{c}(1) \\
\text { Dependent } \\
f_{I} \\
\end{array}$ & $\begin{array}{c}(2) \\
\text { Variable: } \\
f_{I I} \\
\end{array}$ \\
\hline \multicolumn{3}{|l|}{ Panel I: Interacting OADR with Cohorts } \\
\hline OADR \#young & $\begin{array}{c}-0.255^{* * *} \\
(0.067)\end{array}$ & $\begin{array}{c}-0.114^{* * *} \\
(0.039)\end{array}$ \\
\hline$(\mathrm{OADR})^{2}$ \#young & $\begin{array}{c}0.004^{* * *} \\
(0.001)\end{array}$ & $\begin{array}{c}0.002^{* *} \\
(0.001)\end{array}$ \\
\hline Critical OADR & 31.88 & 28.50 \\
\hline OADR \#old & $\begin{array}{c}-0.257^{* * *} \\
(0.066)\end{array}$ & $\begin{array}{c}-0.115^{* * *} \\
(0.039)\end{array}$ \\
\hline$(\mathrm{OADR})^{2} \#$ old & $\begin{array}{c}0.004^{* * *} \\
(0.001)\end{array}$ & $\begin{array}{c}0.002^{* *} \\
(0.001)\end{array}$ \\
\hline Critical OADR & 32.13 & 28.75 \\
\hline Observations & 266,706 & 257,399 \\
\hline \multicolumn{3}{|l|}{ Panel II: Splitting the Sample in Cohorts } \\
\hline OADR young & $\begin{array}{c}-0.255^{* * *} \\
(0.064)\end{array}$ & $\begin{array}{c}-0.114^{\text {*** }} \\
(0.039)\end{array}$ \\
\hline$(\mathrm{OADR})^{2}$ young & $\begin{array}{c}0.004^{* * *} \\
(0.001)\end{array}$ & $\begin{array}{c}0.002^{* *} \\
(0.001)\end{array}$ \\
\hline Critical OADR & 31.88 & 28.50 \\
\hline Observations & 208,697 & 203,144 \\
\hline OADR old & $\begin{array}{c}-0.259^{* * *} \\
(0.071)\end{array}$ & $\begin{array}{c}-0.120^{* * *} \\
(0.037)\end{array}$ \\
\hline$(\mathrm{OADR})^{2}$ old & $\begin{array}{c}0.004^{* * *} \\
(0.001)\end{array}$ & $\begin{array}{c}0.002^{* * *} \\
(0.001)\end{array}$ \\
\hline Critical OADR & 32.33 & 30.00 \\
\hline Observations & 58,009 & 54,255 \\
\hline
\end{tabular}

Summary: This table discusses whether the U-shaped effect of societal population aging on individual attitudes towards immigrants is driven by the young or the old cohort in the sample. Controls are the same as in our benchmark analysis. All regressions feature time and country fixed effects. Panel I interacts the OADR with the young and the old cohorts. Panel II splits the sample in two parts, the young and the old cohorts.

Notes: (i) OADR is the ratio of the population aged 65 and over to the population 15-64 stated as the number of dependents per 100 persons of working age; (ii) $f_{I}$ includes the attitudes 1,2 and 3; (iii) $f_{I I}$ includes the attitudes 4,5 and 6; (iv) standard errors are clustered at country and year level; (v) robust and clustered standard errors are reported in parentheses; (vi) *** denotes statistical significance at the 1 percent level $(p<0.01),{ }^{* *}$ at the 5 percent level $(p<0.05)$, and ${ }^{*}$ at the 10 percent level $(p<0.10)$, all for two-sided hypothesis tests. 


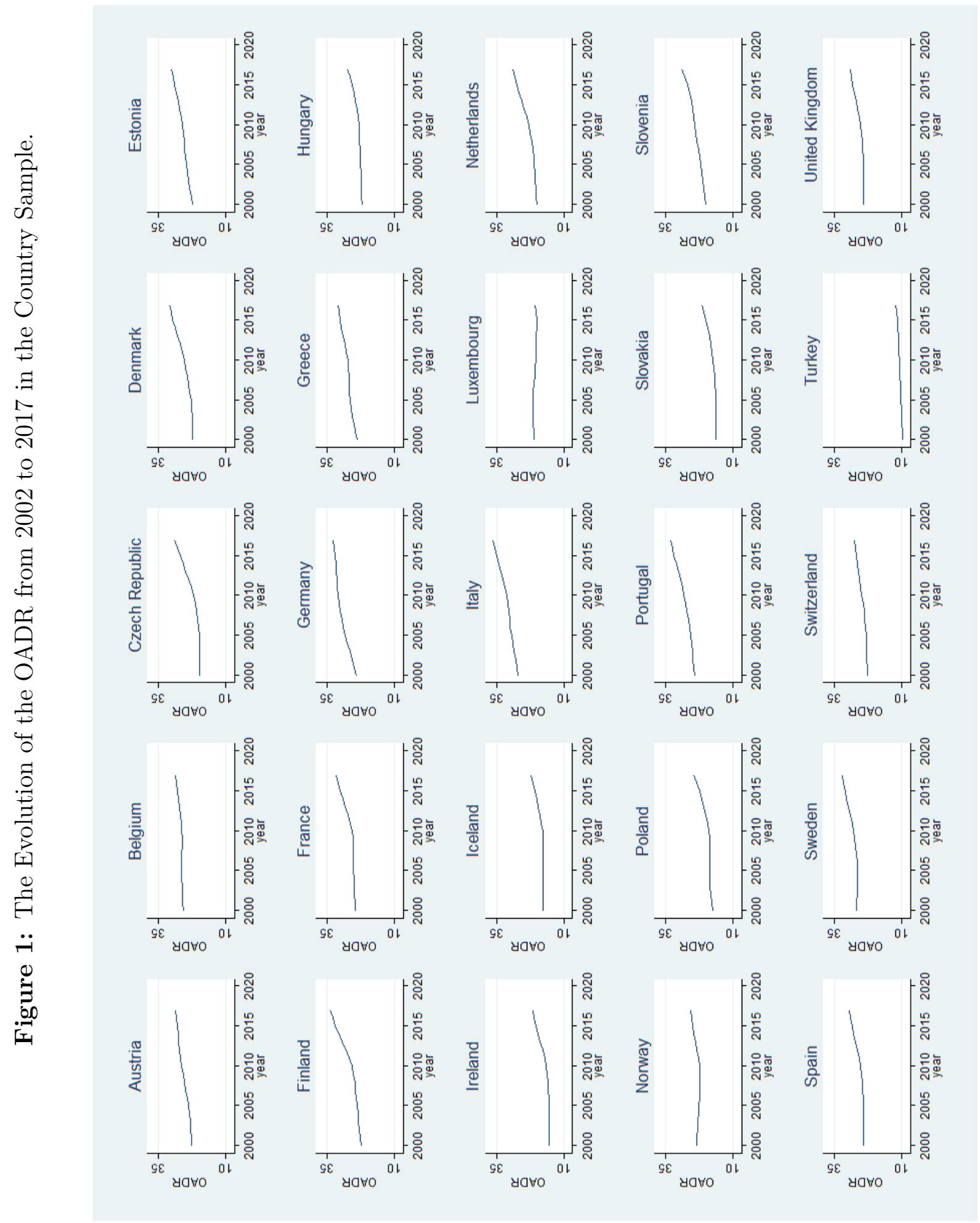


Figure 2: The Critical OADR. The relationship between an attitude towards immigration and OADR is U-shaped. The critical OADR is given by $\hat{\Omega}=-\beta_{1} /\left(2 \beta_{2}\right)$. To the left of this value, societal population aging, i. e., a small increase in the OADR, implies a more negative attitude towards immigration. To the right, the opposite holds.

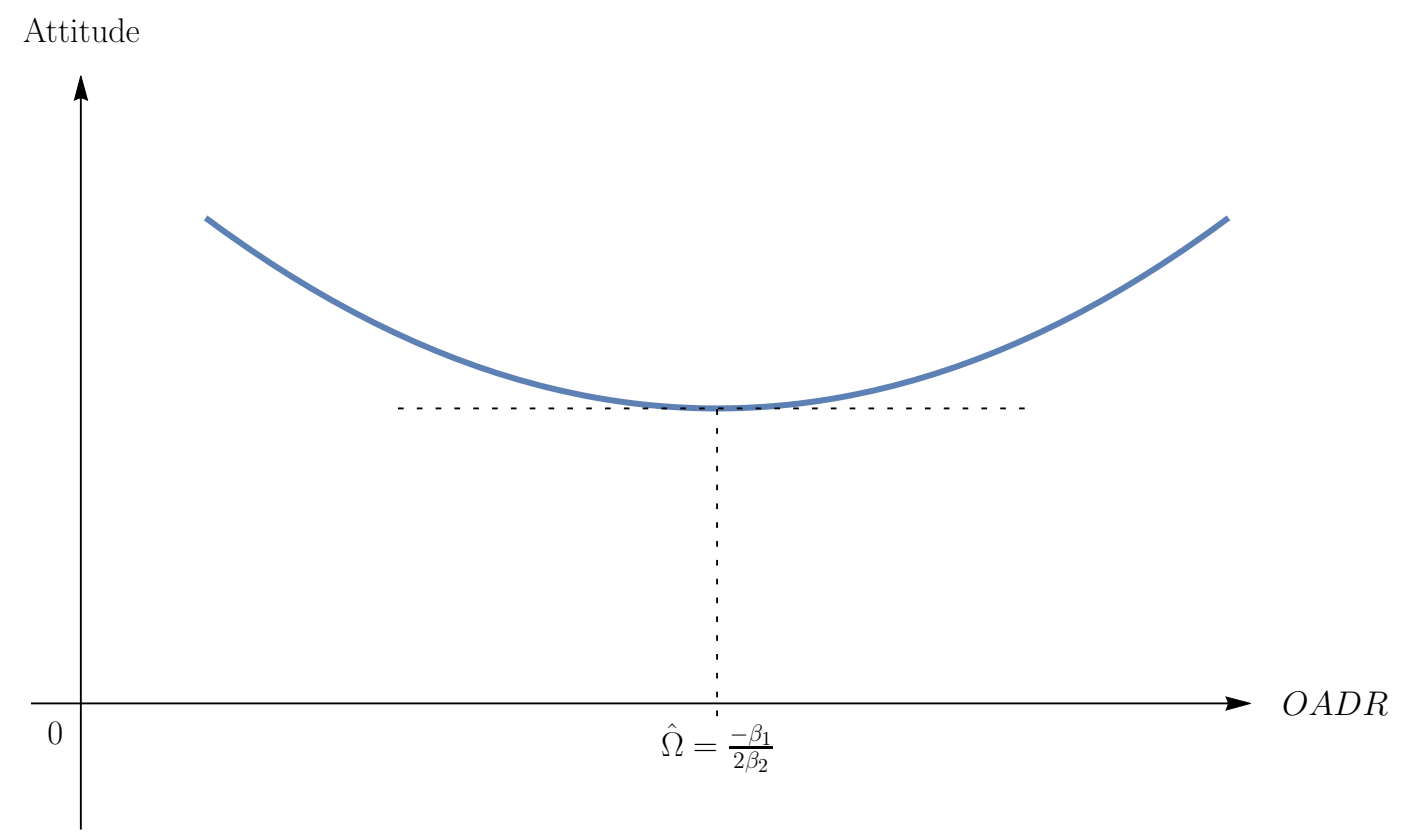




\section{References}

Bloom, D. E., D. Canning, G. Fink, and J. E. Finlay (2008, November). Demographic Change, Institutional Settings, and Labor Supply. PGDA Working Papers 4208, Program on the Global Demography of Aging.

Boeri, T. (2010, October). Immigration to the Land of Redistribution. Economica 77 (308), 651-687.

Calahorrano, L. (2013). Population Aging and Individual Attitudes toward Immigration: Disentangling Age, Cohort and Time Effects. Review of International Economics 21(2), 342-353.

ESS Round 8: European Social Survey Round 8 Data (2016). Data File Edition 2.1. NSD - Norwegian Centre for Research Data, Norway - Data Archive and distributor of ESS Data for ESS ERIC.

European Parliament (2017). Attitudes towards Immigration in Europe: Myths and Realities. https://www.europeansocialsurvey.org/docs/findings (accessed on August 28, 2018).

European Social Survey Cumulative File, ESS 1-7 (2016). Data File Edition 1.0. NSD - Norwegian Centre for Research Data, Norway - Data Archive and distributor of ESS Data for ESS ERIC.

Ivlevs, A. (2012). Ageing, Local Birth Rates and Attitudes towards Immigration: Evidence from a Transition Economy. Regional Studies 46, 947-959.

Lind, J. T. and H. Mehlum (2010). With or Without U? The Appropriate Test for a U-Shaped Relationship. Oxford Bulletin of Economics and Statistics 72(1), 109-118.

OECD (2018). International Migration Database.

Schotte, S. and H. Winkler (2016). Why are the Elderly more Averse to Immigration When They are More Likely to Benefit? Evidence across Countries. World Bank Group, Policy Research Working Paper 7554.

Sides, J. and J. Citrin (2007). European Opinion About Immigration: The Role of Identities, Interests and Information. British Journal of Political Science 37, 477-504.

Talo, T. (2017). Public Attitudes to Immigration in Germany in the Aftermath of the Migration Crisis. European University Institute, Policy Brief 2017/23. 
The Economist (2015). The European Refugee Crisis. https://www.economist.com/migrationcrisis (accessed on August 28, 2018).

Tversky, A. and D. Kahneman (1973). Availability: A Heuristic for Judging Frequency and Probability. Cognitive Psychology 4, 207-232.

WDI (2017). World Development Indicators, The World Bank. 